\title{
Fine-scale analyses of diving energetics in king penguins Aptenodytes patagonicus: how behaviour affects costs of a foraging dive
}

\author{
L. G. Halsey ${ }^{1, *}$, Y. Handrich ${ }^{2}$, A. Fahlman ${ }^{3}$, A. Schmidtt ${ }^{4}$ C.-A. Bost ${ }^{2}$, R. L. Holder ${ }^{5}$, \\ A. J. Woakes ${ }^{1}$, P. J. Butler ${ }^{1}$ \\ ${ }^{1}$ Centre for Ornithology, School of Biosciences, University of Birmingham, Edgbaston B15 2TT, UK \\ ${ }^{2}$ Institut Pluridisciplinaire Hubert Curien (IPHC), UMR 7178 CNRS-ULP, Département Ecologie, \\ Physiologie et Ethologie (DEPE), 23 rue Becquerel, 67087 Strasbourg Cedex 02, France \\ ${ }^{3}$ North Pacific Universities Marine Mammal Research Consortium, UBC Marine Mammal Research Unit, 2202 Main Hall, \\ V6T 1 Z4 Vancouver, British Columbia, Canada \\ ${ }^{4}$ Centre d'Etudes Biologiques de Chizé-Centre National de la Recherche Scientifique, Villiers en Bois, \\ 79360 Beauvoir Sur Niort Cedex, France \\ ${ }^{5}$ Department of Primary Care and General Practice, University of Birmingham, Edgbaston B15 2TT, UK
}

\begin{abstract}
Heart rate data loggers were implanted into king penguins Aptenodytes patagonicus undertaking foraging trips at sea during three austral summers. Data were obtained from a total of 20 king penguins. Our aim was to investigate variations in mean heart rate over the dive cycle (i.e. dive plus the subsequent surface period) with changes in diving behaviour, at the scale of the individual foraging dive. From these heart rate values, energetic costs were estimated in terms of rate of oxygen consumption. Shorter dive durations and longer surface durations were associated with statistically significantly higher mean heart rates, and hence energetic costs, over the dive cycle. A decrease in the duration of the bottom period of dives was also associated with an increase in heart rate and energetic costs. In contrast to model predictions that power requirements of swimming in penguins increase rapidly with increasing speed, in the main, the number of wiggles (i.e. intensive prey pursuits lasting several seconds) in a dive did not affect mean heart rate. Furthermore, the shape of the dive did not affect mean heart rate. Diving behaviour and mean heart rates over the dive cycle of birds during 2 austral summers was compared. While the birds in the earlier austral summer undertook considerably longer foraging trips than did the birds in the latter summer, mean mass gain while at sea was similar. Birds during the latter summer exhibited statistically significantly longer dive durations and bottom durations and dived to statistically significantly shallower depths than birds during the earlier summer. However, this did not translate into a statistically significantly lower mean heart rate over the dive cycle in these birds. This suggests that the differences in dive time budgeting between the two summers had only a relatively subtle effect on mean heart rate. In turn the relationship between diving behaviour and foraging success in king penguins may be more obvious than that between diving behaviour and mean heart rate over the dive cycle.
\end{abstract}

KEY WORDS: Diving behaviour $\cdot$ Energetics $\cdot$ King penguin $\cdot$ Oxygen consumption $\cdot$ Foraging behaviour Resale or republication not permitted without written consent of the publisher

\section{INTRODUCTION}

An understanding of the relationships between prey availability and predator performance is essential when using predators as indicators of marine systems
(Croxall et al. 1999). Penguins represent up to $90 \%$ of the avian biomass in the Southern Ocean (Woehler 1995) and consume key species in the trophic chains of these waters. This makes them prime candidates for use as bio-indicators of the Antarctic ecosystem 
and, as such, it is important that useful inferences can be made about their food requirements (Croxall et al. 1999). One way to assess food requirements is to accurately measure total metabolic rate, and an important element of this rate for penguins is associated with foraging.

King penguins Aptenodytes patagonicus are a relatively well studied penguin species. Their diving behaviour and associated energetic costs have been investigated both under laboratory conditions (Culik et al. 1996) and in the field (Kooyman et al. 1992, Froget et al. 2004). Froget et al. (2004) measured heart rate $\left(f_{\mathrm{H}}\right)$ to estimate metabolic rate in king penguins, a technique that has been used successfully on a number of marine species (Bevan et al. 1995, 2002, Boyd et al. 1995, Green et al. 2003). Froget et al. (2004) estimated the overall energy costs of king penguins while undertaking foraging trips at sea. However, knowledge of energy costs of foraging at a fine temporal resolution is required to help fully elucidate the feeding ecology of seabird species (Le Maho et al. 1993, Froget et al. 2004) through a better understanding of how variation in foraging strategies affects foraging energetics (Hastie et al. 2006). This is an important step in the increasing effort to use seabirds as indicators of variation in ocean resources (Ropert-Coudert et al. pers. comm.), particularly once accurate information on their food requirements is available. However, as yet there is no information on the cost of diving for king penguins at the scale of individual dives. Indeed, detailed analysis of diving costs at a fine temporal scale has not yet been undertaken for any freely diving species.

Like other penguin species, king penguins undertake a wide variety of different dives in terms of depth, duration, shape and function. Dives with a maximum depth greater than $50 \mathrm{~m}$ are classed as deep dives and are considered to constitute the majority of foraging dives of king penguins (Pütz et al. 1998, Ropert-Coudert et al. 2000a). Dives to over $250 \mathrm{~m}$ have been recorded (e.g. Kooyman \& Davis 1982, Kooyman et al. 1992, Pütz et al. 1998) particularly at times of the year when prey have migrated to deeper waters (Charrassin et al. 2002) and when king penguins must provision for a chick (Charrassin et al. 1998). There are also believed to be different shapes of foraging dives undertaken by penguins reflecting different strategies employed to seek out and capture prey (Wilson 1995). For example, Wilson (1995) identified U- and W-shape dives, with prey pursuit occurring predominantly during ascent in U-shape dives and during the bottom phase in W-shape dives (Pütz \& Cherel 2005). Furthermore, at all dive depths and for all types of dives, the duration of those dives can also vary considerably (Kooyman et al. 1992), probably at least partially due to concentrations of prey in patches visited (Charrassin et al. 2002). Therefore, when king penguins are foraging at sea, the characteristics of each individual foraging dive is determined by a multitude of behavioural variables.

The time budgets and maximal depths of foraging dives may have a large effect on their energetic costs. For example, there is evidence to suggest that the rate of energy expenditure during longer dives of diving birds is less than that during shorter dives (Bevan et al. 1992, Green et al. 2003) and that for diving animals in general, dives to a greater depth are energetically more costly than those of similar duration to shallower depths (Halsey et al. 2006). There may also be a difference in the energy costs of different types of foraging dives.

King penguins feed on small schooling fish, the myctophids (Cherel \& Ridoux 1992). Although it is not yet clear exactly how they capture these fish, it is known that, at least some of the time, they make relatively small but rapid adjustments to their position in the water column just before they ingest prey (Bost et al. 2007) and, on some occasions, may undertake intensive prey pursuits for several seconds while ascending (Ropert-Coudert et al. 2000b). These types of events, known as 'wiggles', may involve an increase in energetic output in order to produce the acceleration that characterises them and the degree of increase is possibly affected by other factors such as the depth, and hence the buoyancy, of the penguin. The number of wiggles in a dive may also therefore have an important influence on the energy expended by king penguins during foraging dives.

It might therefore be reasonable to suppose that the energetic costs of individual dives by king penguins can vary considerably. It has been shown that over complete dive cycles (dive plus the subsequent surface period), mean $f_{\mathrm{H}}$ can be used to estimate rate of oxygen consumption ( $\dot{V}_{\mathrm{O}_{2}}$ ) (Bevan et al. 1992), which is an indirect measure of metabolic rate and can be converted to rate of energy expenditure. The deployments of depth and heart rate data loggers in king penguins over recent years have yielded an extensive set of data for a number of birds that allow comprehensive analysis of $f_{\mathrm{H}}$ and foraging behaviour at a high temporal resolution. The overall objective of the present study was to investigate variations in mean $f_{\mathrm{H}}$ over the dive cycle $\left(f_{\mathrm{Hdc}}\right)$ in king penguins at the scale of the individual foraging dive and from these values to estimate the energetic costs of dives in terms of $\dot{V}_{\mathrm{O}_{2}}$ ( $\dot{V}_{\mathrm{O}_{2}}$ est). Three questions were addressed: (1) How do differences in the time budgets and depths of foraging dives affect $f_{\mathrm{Hdc}}$ and $\dot{V}_{\mathrm{O}_{2}}$ of those dives? (2) Does the number of wiggles affect $f_{\mathrm{Hdc}}$ and $\dot{V}_{\mathrm{O}_{2}}$ during foraging dives? (3) Do foraging dives of different shape have different $f_{\mathrm{Hdc}}$ and $\dot{V}_{\mathrm{O}_{2}}$ ? 


\section{MATERIALS AND METHODS}

Study birds. The study was undertaken at the French station on Possession Island $\left(46^{\circ} 25^{\prime} \mathrm{S}, 51^{\circ} 45^{\prime} \mathrm{E}\right)$, Crozet Archipelago, during 3 consecutive austral summers (2002-2003, 2003-2004, 2004-2005). King penguins, used in the study were male birds at the colony of La Baie du Marin; 26 penguins were captured either while brooding an egg (first field season) or during early courtship (second and third field seasons). They were each implanted with a custom-built $f_{\mathrm{H}}$ and depth data logger (Woakes et al. 1995); 8 birds in 2002-2003, 10 birds in 2003-2004, and 8 birds in 2004-2005 (mean mass $\pm \mathrm{SEM}=14.1 \pm 0.1 \mathrm{~kg}$ ). After implantation, the penguins were marked on their chest with picric acid to aid in identification and recapture after their return from a foraging trip at sea. Immediately after surgery, brooding birds were replaced at the exact site of capture and their egg returned. They undertook a foraging trip at sea 15 to $20 \mathrm{~d}$ later, after exchanging the egg with their mate. Courting birds were placed back in a pen and fasted until their weights were within $15 \%$ above their critical Mb (body mass) (Gauthier-Clerc et al. 2001), which took between 1 and $2 \mathrm{wk}$. They were then released onto the beach close to where they had been captured. Their weights at this time ensured that they returned to sea to forage in order to re-instigate a breeding attempt. Within $24 \mathrm{~h}$ of each bird returning from a foraging trip at sea, it was recaptured and weighed. Shortly after this the bird underwent surgery for removal of the logger.

Heart rate data loggers. The heart rate data loggers $\left(30 \times 25 \times 15 \mathrm{~mm}\right.$ and $30 \mathrm{~g}_{1}<1 \%$ of the mean body mass of a king penguin) had 16 to $64 \mathrm{MB}$ of memory, were able to record $f_{\mathrm{H}}$ and hydrostatic pressure (to an accuracy of $1 \mathrm{~m}$ depth) and were programmed to record these measurements at a frequency of $1 \mathrm{~Hz}$. After programming the loggers, they were encapsulated in wax and coated with medical grade silicone rubber. Prior to implantation, the logger was bathed in a cold sterilising solution for 1 to $2 \mathrm{~h}$, and then rinsed thoroughly with sterile saline solution.

Surgical procedure. For details of the implantation procedure, see Froget et al. (2004) and Fahlman et al. (2005). The procedures for the removal of the logger and for the replacement of the bird in the colony after surgery were similar to those for implantation, except that brooding birds had to be recaptured and then returned with their chick. After retrieval, data from all loggers were downloaded onto a computer and then analysed.

Data analysis. All 26 loggers were recovered, of which 20 had recorded usable data. Data from these loggers were extracted and prepared and initially analysed using purpose-written computer programs in Matlab (Version 6.0, MathsWorks). Further analyses involved general linear modelling, 1-way ANOVAs and
Student's $t$-tests, and were performed in the statistical packages Minitab (Version 14.1, Minitab) and JMP (Version 5.1, SAS Institute).

Dive analysis. Dives with maximum depths greater than $50 \mathrm{~m}$ were used for analysis (considered to represent the majority of foraging dives of king penguins; Pütz et al. 1998, Ropert-Coudert et al. 2000a), totalling 23040 dives. The following diving parameters were used to describe each dive: dive duration (s), subsequent surface duration (until the next dive of any depth; other definitions of surface duration are also possible; Halsey et al. in press), bottom duration (s), maximum depth $(\mathrm{m})$, number of wiggles during the dive and dive shape. These data formed the diving variables used in the analyses of the present study. Dive shape was categorised as either $\mathrm{u}, \mathrm{U}$ or $\mathrm{W}$, using criteria based on those detailed in Halsey et al. (in press), which classifies dive shape based on wiggles and other events within the dive. Briefly, u-dives are relatively smooth dives with a fairly consistent change in vertical speed throughout the dive, U-dives are the modal foraging dive when such a classification of dive shape is used, and W-dives include a bottom period during which depth varies considerably over time. The bottom phase of dives and the wiggles within dives were also identified using the criteria detailed in Halsey et al. (in press). Briefly, wiggles are a particular pattern in the depth profile over time during a dive where an increase in depth over time changes to a decrease in depth and then back to an increase in depth. This creates a short period in the dive profile that is concave in shape. Wiggles are defined as elements of the dive profile during which at 3 points the vertical speed passes below $0 \mathrm{~m} \mathrm{~s}^{-1}$. The bottom phase was identified as being from the first wiggle in the deepest $25 \%$ of the dive to the last wiggle within this same depth range. Bout criterion interval analysis (Slater \& Lester 1982) was used to eliminate all dives with surface periods that represented pauses between bouts (Halsey et al. 2003). All dives were also linked to an individual bird, the field season of data collection, and a unique diving bout number, since it is reasonable to suppose that all these factors could have an effect on the relationship between $f_{\mathrm{Hdc}}$ and diving variables.

A general linear model (GLM), using Type III testing, was then developed to answer the 3 questions posed about $f_{\mathrm{H}}$ during diving of king penguins. This model examined how specific diving variables affect $f_{\mathrm{Hdc}}$ (heart beats $\mathrm{min}^{-1}$ ), both in their own right and through interactions with other diving variables. When examining the influence of each diving variable on $f_{\mathrm{Hdc}}$, the GLM controlled for the other variables. Thus this approach to analysing the data provides a powerful method for investigating how each diving variable independently affects $f_{\text {Hdc }}$. The GLM allowed for dif- 
ferences between the field season during which the data were collected, individual birds and diving bouts. There was no evidence from the analysis software of a problem due to the multicollinearity of the variables.

While some of the variables included in analyses were categorical variables, such as field season and bout number, many of the variables were continuous such as dive duration. To identify not only the presence but also the nature of the statistically significant main effects of these variables, and the statistically significant interactions between these variables, all continuous variables were binned to produce categorical variables. This enabled, for example, the approximate range to be ascertained over which 1 diving variable exerted influence on how another diving variable was related to $f_{\mathrm{Hdc}}$. Therefore, only categorical variables were input to the GLM. To categorise each continuous variable, the data were divided into 3 bins. The ranges of each bin were selected to ensure that (1) a sufficient number of data points was present in each when the interactions between 2 variables were analysed and that these represented at least a large number of individual birds, and (2) each bin represented ranges of the data that were likely to reveal differences (if they existed) when the bins were compared, since the differences could exist throughout an interaction, in a central portion or at an extremity. Thus there were necessarily large differences in the number of data points between certain bins. The means \pm SEM and the ranges of each binned variable are shown in Table 1.

For each individual, the distribution of all dive durations was not normal. After categorising the dives into 3 maximum dive depth bins (Table 1), the distribution of each depth bin was unimodal and appeared normal (assessed by visual examination of frequency, box,
$\mathrm{Q}-\mathrm{Q}$ and $\mathrm{P}-\mathrm{P}$ plots). Preliminary plots of the residuals of the dependent variable against the predicted value of the dependent variable indicated mild heteroscedasticity in the data. However, the continuous variables were categorised using bins, nullifying the effect of transforming the data. Thus, only the dependent variable $\left(f_{\mathrm{Hdc}}\right)$, which was input to the GLM in a continuous format, was log-transformed beforehand. In all analyses, dives were treated as independent events, an assumption that is required to perform further statistical analyses (Green et al. 2003).

Only second-degree interaction terms were input to the GLM, and variation not accounted for by the subsequent best fit model was considered to be noise in the data. A plausible best fit model was achieved by firstly including all possible main effects and all possible second degree interactions in the model and then removing non-significant terms, 1 iteration at a time, by backwards elimination. Backwards elimination allows control over which factors are retained and removed. Non-significant main effects were kept if the variable in question was part of a statistically significant interaction. Thus all interaction terms included in the best fit model are statistically significant .

The GLM and the associated post hoc analyses of the large data set of the present study is necessarily complex. In the present paper, interpretation of such analyses was based on drawing out the points of biological interest within the data. This was achieved through firstly studying the trends in mean $f_{\mathrm{Hdc}}$ for each bin of each diving variable, derived by taking means for each bird and then producing a grand mean. However, statistical analysis of the data was undertaken through the GLM and post hoc tests so that the independent effects of each diving variable could be investigated.

Table 1. Aptenodytes patagonicus. Ranges and overall means \pm SEM of continuous variables measuring diving behaviour during foraging dives and means \pm SEM for each variable, categorised into 3 bins. Data for 20 king penguins. Values in parentheses indicate number of dives

\begin{tabular}{|c|c|c|c|c|}
\hline Variable & Overall & Bin 1 & Bin 2 & Bin 3 \\
\hline \multicolumn{5}{|c|}{ Dive duration (s) } \\
\hline Range & $75.0-491.0$ & $75-200$ & $201-280$ & $>280$ \\
\hline Mean & $248.4 \pm 3.8$ & $182.3 \pm 1.1(3345)$ & $239.0 \pm 0.8(14084)$ & $314.3 \pm 2.2(5611)$ \\
\hline \multicolumn{5}{|c|}{ Surface duration (s) } \\
\hline Range & $5.0-119.0$ & $5-40$ & $41-70$ & $>70$ \\
\hline Mean & $47.9 \pm 1.9$ & $21.1 \pm 0.8(9118)$ & $55.7 \pm 0.2(7909)$ & $86.3 \pm 0.7(5102)$ \\
\hline \multicolumn{5}{|c|}{ Bottom duration (s) } \\
\hline Range & $8.0-242.0$ & $8-60$ & $61-120$ & $>120$ \\
\hline Mean & $71.3 \pm 2.1$ & $46.5 \pm 1.5(10581)$ & $89.4 \pm 2.2(11360)$ & $140.7 \pm 7.6(1099)$ \\
\hline \multicolumn{5}{|c|}{ Maximum dive depth (m) } \\
\hline Range & $50.0-329.0$ & $50-110$ & $111-170$ & $>170$ \\
\hline Mean & $127.0 \pm 5.3$ & $85.9 \pm 1.2(9625)$ & $135.8 \pm 1.0(9454)$ & $196.5 \pm 3.1(3961)$ \\
\hline \multicolumn{5}{|c|}{ Number of wiggles } \\
\hline Range & $1-23$ & $0-6$ & $7-10$ & $>10$ \\
\hline Mean & $4.9 \pm 0.2$ & $3.7 \pm 0.1(16363)$ & $7.8 \pm 0.1(4945)$ & $11.9 \pm 0.1(1732)$ \\
\hline
\end{tabular}


The relevant factorial plots of main effects and interactions were examined to identify the statistically significant variations in the data representing differences that were biologically meaningful (Green et al. 2005). The factorial plots of the statistically significant main effects of the GLM were similar to the mean values of $f_{\mathrm{Hdc}}$ for each of the 3 bins for each diving variable. For comparison, both sets of values are reported, and the differences helped to draw out and explain some of the points of interest in the data. Factorial plots of statistically significant, biologically interesting interactions are also shown.

While statistically significant differences in $f_{\mathrm{Hdc}}$ suggest significant differences in energy expenditure over the dive cycle, i.e. in the energy costs of diving, quantification of diving costs in terms of rate of oxygen consumption is possible once $\dot{V}_{\mathrm{O}_{2}}$ has been estimated. $\dot{V}_{\mathrm{O}_{2}}$ is an indirect measure of metabolic rate that can be converted to rate of energy expenditure, although this requires additional assumptions concerning the metabolic substrate being utilised (Walsberg \& Hoffman 2005). Estimates of $\dot{V}_{\mathrm{O}_{2}}$ from mean $f_{\mathrm{Hdc}}$ for each bin of each diving variable were achieved using Conversion Eq. (1) derived in Fahlman et al. (2004), which is suitable for king penguins exercising in water (Halsey et al. 2007). Firstly, this provides a quantification of the costs of the dives. Secondly, values of $\dot{V}_{\mathrm{O}_{2}}$ est were statistically compared for bins of those diving variables that represented statistically significant main effects in the GLM. Standard errors of $\dot{V}_{\mathrm{O}_{2}}$ est (SEE) were calculated using the equation based on that derived in Green et al. (2001) and which was further developed and detailed in Froget et al. (2004). To compare values of $\dot{V}_{\mathrm{O}_{2}}$ est, a form of the proximate normal test for comparing the differences between 2 estimates was used (Green et al. 2001, Froget et al. 2004). Differences were considered statistically significant when $Z>1.96$ (i.e. $\mathrm{p}<0.05$ ).

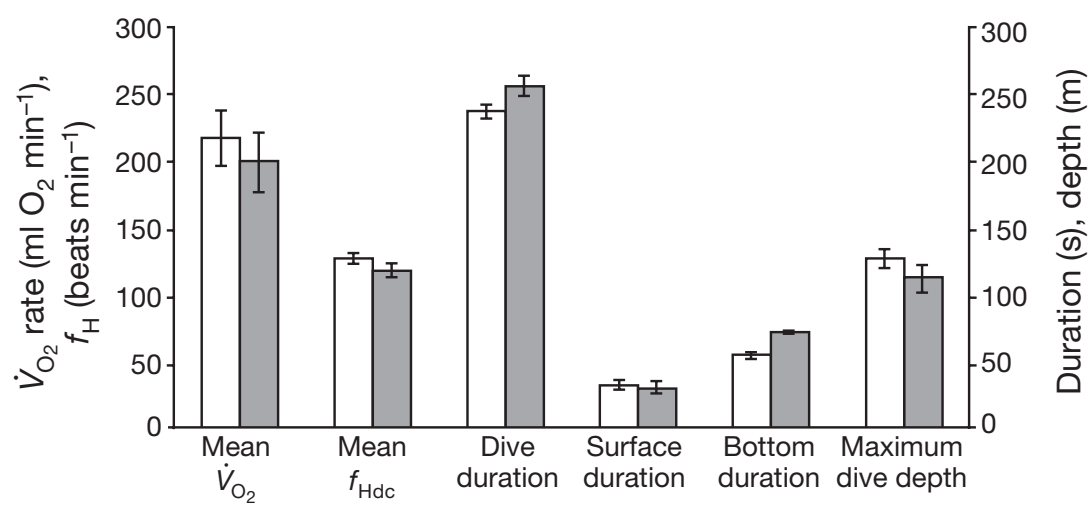

Fig. 1. Aptenodytes patagonicus. Overall means ( \pm SEM or SEE, as appropriate) of variables measuring diving behaviour of foraging dives over dive cycle that can have an important influence on $\dot{V}_{\mathrm{O}_{2}}$ of dive cycle. Open and grey bars represent Field Seasons 2 and 3, respectively

\section{RESULTS}

The duration of the data recorded varied from 5 to $42 \mathrm{~d}$. In the first field season, the birds spent on average $21 \pm 1$ days at sea, in the second field season they spent on average $32 \pm 3$ days at sea and in the third field season, $9 \pm 1$ days at sea. In the second field season the birds gained $3.26 \pm 0.27 \mathrm{~kg}$ in mass during the period at sea and $3.23 \pm 0.21 \mathrm{~kg}$ in the third field season. (The masses of the birds in the first season were not known just prior to their going to sea because they were brooding in the colony). Comparisons of dive time budgeting were made between Field Seasons 2 and 3 (Fig. 1). Mean dive duration was statistically significantly longer in Field Season $3\left(t_{13}=2.199\right.$, $\mathrm{p}<0.05)$, as was mean bottom duration $\left(t_{13}=5.459\right.$, $\mathrm{p}<0.001)$. There were no statistically significant differences in mean surface duration or mean maximum dive depth. Mean number of wiggles per dive was statistically significantly higher in Field Season 3 (4.6 \pm 0.2 vs. $\left.3.5 \pm 0.1 ; t_{13}=5.403, \mathrm{p}<0.001\right)$. There was a statistically significant difference in the mean number of wiggles between all 3 dive shapes (u: $2.3 \pm 0.2$; $\mathrm{U}: 4.8 \pm 0.2 ; \mathrm{W}: 6.7 \pm 0.2 ; F_{2}=116.5, \mathrm{p}<0.001$, all post hoc Tukey tests: $\mathrm{p}<0.001$ ).

Table 2 shows mean $f_{\mathrm{Hdc}}$ for each bin of each diving variable and the values of $\dot{V}_{\mathrm{O}_{2}}$ est calculated from these mean $f_{\mathrm{Hdc}}$ values. Clearly, there is considerable variation between some of the bins within diving variables and an indication of variability between some others. To investigate this further a GLM analysis was conducted (Table 3). Fig. 2 shows the main effect plots of the diving variables, which differ subtly, and sometimes importantly, from the mean $f_{\mathrm{Hdc}}$ values for the binned data in Table 2. A number of key and important features from the GLM can be identified, to answer the questions posed at the outset of this study, i.e. (1) How do differences in the time budgets and depths of foraging dives affect $f_{\mathrm{Hdc}}$ and $\dot{V}_{\mathrm{O}_{2}}$ of those dives? (2) Does the number of wiggles affect $f_{\mathrm{Hdc}}$ and $\dot{V}_{\mathrm{O}_{2}}$ during foraging dives? (3) Do foraging dives of different shape have different $f_{\mathrm{Hdc}}$ and $\dot{V}_{\mathrm{O}_{2}}$ ?

In relation to Questions 1 to 3:

- There were no statistically significant differences in $f_{\mathrm{Hdc}}$ between field seasons.

In relation to Question 1:

- There were statistically significant differences in $f_{\mathrm{Hdc}}$ between dive cycles of different dive and surface duration. $f_{\mathrm{Hdc}}$ decreased as dive duration increased and as surface duration decreased. 
Table 2. Aptenodytes patagonicus. Means \pm SEM of mean heart rate, $f_{\mathrm{H}}$ (heartbeats $\left.\mathrm{min}^{-1}\right)$, per bird, over the dive cycle $\left(f_{\mathrm{Hdc}}\right)$ of foraging dives and mean \pm SEE estimated oxygen consumption, $\dot{V}_{\mathrm{O}_{2}}$ est $\left(\mathrm{ml} \mathrm{O}_{2} \mathrm{~min}^{-1}\right)$, over the dive cycle calculated therefrom. Bin classification of each diving variable as in Table 1. Data for $20 \mathrm{king}$ penguins. Values in parentheses following $f_{\mathrm{H}}$ values indicate number of dives. ${ }^{*}$ Statistically significant differences between value and equivalent value in Bin 3, p $<0.05$

\begin{tabular}{|c|c|c|c|c|c|c|}
\hline & Dive duration & Surface duration & Bottom duration & $\begin{array}{l}\text { Maximum } \\
\text { dive depth }\end{array}$ & $\begin{array}{l}\text { Number } \\
\text { of wiggles }\end{array}$ & Dive shape - \\
\hline \multicolumn{7}{|l|}{ Bin 1} \\
\hline$f_{\mathrm{Hdc}}$ & $142.6 \pm 3.1(3345)$ & $119.1 \pm 3.1(9118)$ & $132.1 \pm 3.1(10581)$ & $133.0 \pm 3.1(9625)$ & $130.0 \pm 3.3(16363)$ & u $127.1 \pm 3.5(1346)$ \\
\hline$\dot{\mathrm{V}}_{\mathrm{O}_{2}}$ & $246.7(+16.3,-15.3)^{*}$ & $197.3(+13.0,-12.2)^{*}$ & $224.3(+15.5,-14.5)$ & $226.2(+15.7,-14.7)$ & $219.9(+15.1,-14.1)$ & $213.9(+14.5,-13.6)$ \\
\hline \multicolumn{7}{|l|}{ Bin 2} \\
\hline$f_{\mathrm{Hdc}}$ & $131.0 \pm 2.9(14084)$ & $135.5 \pm 3.2(7909)$ & $128.6 \pm 3.4(11360)$ & $131.2 \pm 3.4(9454)$ & $130.6 \pm 3.2(4945)$ & U $130.3 \pm 3.2(20410)$ \\
\hline$V_{\mathrm{O}_{2}}$ & $227.2(+15.4,-14.4)$ & $231.5(+16.2,-15.2)$ & $217.0(+14.8,-13.8)$ & $222.5(+15.3,-14.3)$ & $221.2(+15.2,-14.2)$ & $220.6(+15.1,-14.2)$ \\
\hline \multicolumn{7}{|l|}{ Bin 3} \\
\hline$f_{\mathrm{Hdc}}$ & $117.9 \pm 3.6(5611)$ & $139.5 \pm 3.2(5102)$ & $123.5 \pm 3.7$ (1099) & $123.6 \pm 4.5(3961)$ & $129.4 \pm 4.3(1732)$ & W $133.0 \pm 3.2(1284)$ \\
\hline$\dot{\mathrm{O}}_{\mathrm{O}_{2}}$ & $194.8(+12.7,-12.0)$ & $240.0(+16.2,-15.2)$ & $206.4(+13.8,-12.9)$ & $206.6(+13.8,-12.9)$ & $218.7(+14.9,-14.0)$ & $226.2(+15.3,-14.3)$ \\
\hline Overall & $\begin{array}{c}130.1 \pm 3.2 \\
220.1(+15.1,-14.1)\end{array}$ & & & & & \\
\hline
\end{tabular}

Table 3. Aptenodytes patagonicus. Analysis of individual component factors of general linear model (GLM), relating diving variables of foraging dives to $f_{\mathrm{Hdc}}$. $\mathrm{R}^{2}$ of GLM was $80.13 \%$. Statistical significance at ${ }^{*} p<0.05,{ }^{* *} p<0.01$ and ${ }^{* * *} \mathrm{p}<0.001$

\begin{tabular}{|lll|}
\hline Factor & df & \multicolumn{1}{c|}{$\mathrm{p}$} \\
\hline Field season & 2 & 0.386 \\
Bird (Field season) & 17 & $0.000^{* * *}$ \\
Bout no. (Field season, Bird) & 512 & $0.000^{* * *}$ \\
Dive shape & 2 & 0.910 \\
Max. dive depth & 2 & 0.342 \\
Bottom duration & 2 & $0.001^{* *}$ \\
Surface duration & 2 & $0.000^{* * *}$ \\
Dive duration & 2 & $0.000^{* * *}$ \\
No. wiggles & 2 & 0.407 \\
Dive shape $\times$ No. of wiggles & 4 & $0.047^{*}$ \\
Max. dive depth $\times$ Bottom duration & 4 & $0.000^{* * *}$ \\
Max. dive depth $\times$ Surface duration & 4 & $0.001^{* *}$ \\
Max. dive depth $\times$ Dive duration & 4 & $0.011^{*}$ \\
Max. dive depth $\times$ No. of wiggles & 4 & $0.000^{* * *}$ \\
Bottom duration $\times$ Surface duration & 4 & $0.011^{*}$ \\
Bottom duration $\times$ Dive duration & 4 & $0.003^{* *}$ \\
Surface duration $\times$ Dive duration & 4 & $0.000^{* * *}$ \\
Dive duration $\times$ No. of wiggles & 4 & $0.000^{* * *}$ \\
\hline
\end{tabular}

- There were statistically significant differences in $f_{\mathrm{Hdc}}$ between dive cycles with different bottom durations. As bottom duration increased, $f_{\mathrm{Hdc}}$ decreased.

- Although there were some differences in $f_{\mathrm{Hdc}}$ of foraging dives to different depths (Table 2), when variables such as dive duration were accounted for, the effect of depth was not statistically significant (Fig. 2). However, the maximum depth of foraging dives did influence how some other variables affected $f_{\mathrm{Hdc}}$. Maximum dive depth significantly influenced the effect of bottom duration on $f_{\mathrm{Hdc}}$. As foraging dives became deeper, the difference in $f_{\mathrm{Hdc}}$ of dives in relation to bottom duration became more pronounced. In particular, deep foraging dives with long bottom durations had lower $f_{\mathrm{Hdc}}$ than deep foraging dives with short bottom durations (Fig. 3).

In relation to Question 2:

- The number of wiggles in a foraging dive did not affect $f_{\mathrm{Hdc}}$. However, the number of wiggles did have a statistically significant effect, although fairly small, on $f_{\text {Hdc }}$ at deep depths. Specifically, deep foraging dives including a high number of wiggles had a

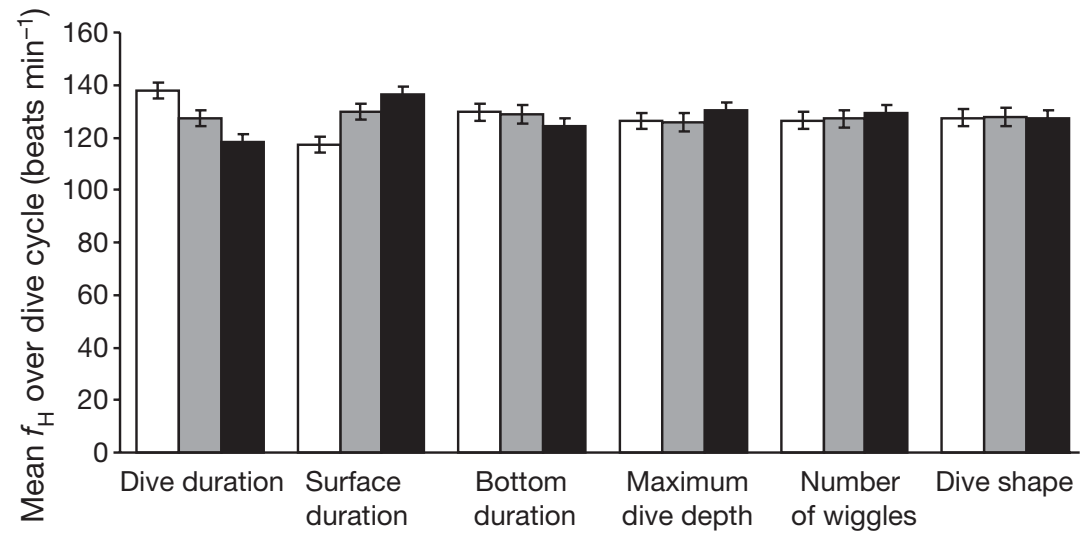

Fig. 2. Aptenodytes patagonicus. Factorial plots of main effects of diving variables as a function of mean $( \pm \mathrm{SEE}) f_{\mathrm{H}}$ over dive cycle of foraging dives (heartbeats $\mathrm{min}^{-1}$ ) where diving variables have been categorised into 3 bins (Table 1). Open, grey and black bars represent Bins 1, 2 and 3, respectively, for all variables except dive shape, where they represent $u, U$ and $W$, respectively 


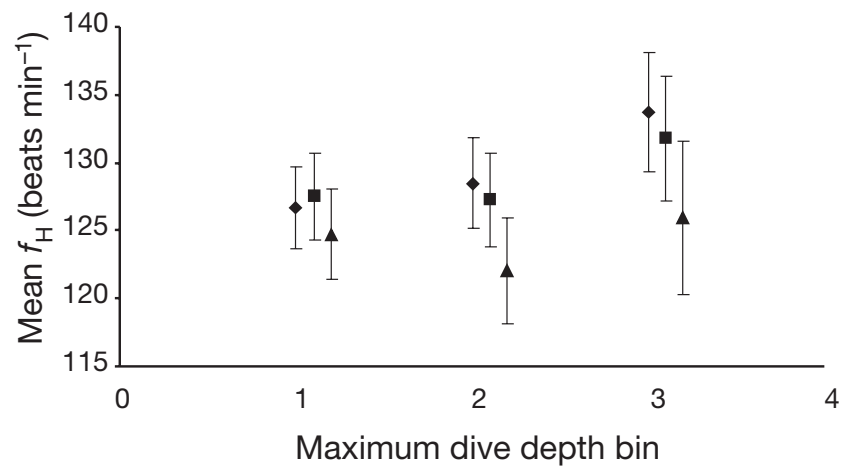

Fig. 3. Aptenodytes patagonicus. Factorial plot of interaction term between bottom duration and maximum dive depth against mean $f_{\mathrm{H}}$ over dive cycle. Means \pm SEE. Bottom durations: $\$$ : 8 to $60 \mathrm{~s}$ (Bin 1); $\square$ : 61 to $120 \mathrm{~s}$ (Bin 2); and $\boldsymbol{\Delta}:>120 \mathrm{~s}(\mathrm{Bin} 3)$

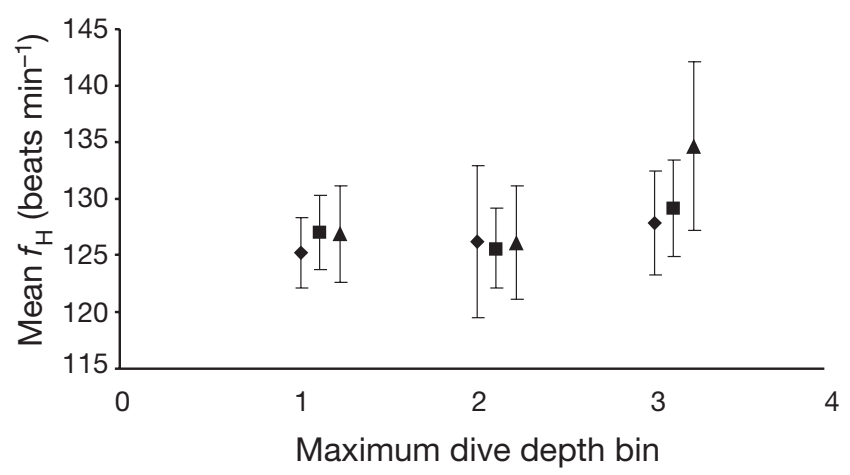

Fig. 4. Aptenodytes patagonicus. Factorial plot of interaction term between number of wiggles and maximum dive depth against mean $f_{\mathrm{H}}$ over dive cycle. Means \pm SEE. $\$$ : 0 to 6 wiggles (Bin 1); $\mathbf{\square}$ : 7 to 10 wiggles (Bin 2); and $\mathbf{\Delta}$ : >10 wiggles (Bin 3)

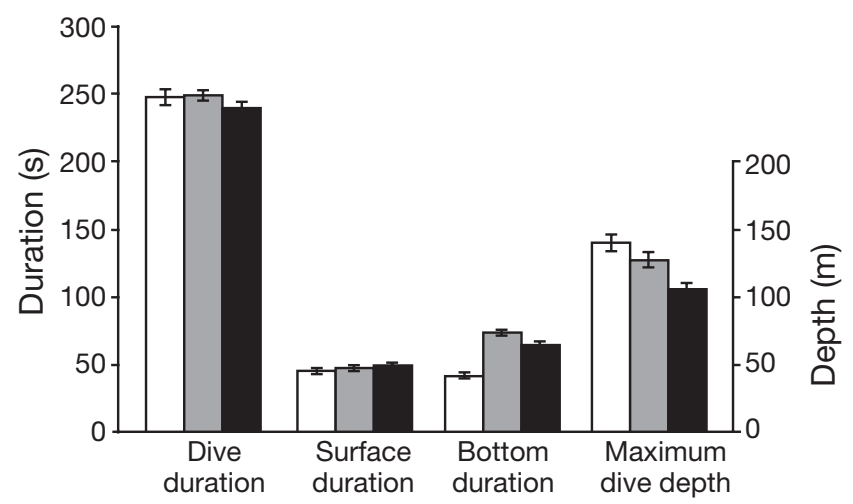

Fig. 5. Aptenodytes patagonicus. Overall means \pm SEM of variables measuring diving behaviour of foraging dives categorised according to dive shape. Open, grey and black bars: $\mathrm{u}-, \mathrm{U}-$ and $\mathrm{W}$-shape dives, respectively higher $f_{\mathrm{Hdc}}$ than similar dives including fewer wiggles (Fig. 4).

In relation to Question 3:

- There were no apparent differences in $f_{\mathrm{Hdc}}$ of different shapes of foraging dives, in particular when accounting for other variables such as the duration and depth of the dive (Fig. 5).

There were statistically significant differences in $\dot{V}_{\mathrm{O}_{2}}$ est between dive duration Bin 1 (75 to $200 \mathrm{~s}$ ) and dive duration Bin 3 (>280 s), and also between surface duration Bin 1 ( 5 to $40 \mathrm{~s}$ ) and surface duration Bin 3 (>70 s) (Z-tests; Table 2).

\section{DISCUSSION}

The analyses of the present study represent the first time that $f_{\mathrm{Hdc}}$ and associated $\dot{V}_{\mathrm{O}_{2}}$ est, during diving in animals in the field have been studied in detail at a fine temporal scale. This is important if we are to understand the potential energetic consequences for major marine predators that change their foraging strategies or are faced with changes in prey dynamics (Hastie et al. 2006). The current study indicates that king penguins exhibit a wide variety of diving behaviours, which have been shown to influence $f_{\mathrm{Hdc}}$ and thus $\dot{\mathrm{V}}_{\mathrm{O}_{2}}$ est during foraging dives in some cases but to have little such influence in other cases.

Because values of $\dot{V}_{\mathrm{O}_{2}}$ est include estimate errors and because they must be calculated from the mean $f_{\mathrm{H}}$ of multiple birds, they could not be incorporated into the GLM. Thus the statistics in the present study investigated the effects of diving variables on $f_{\mathrm{Hdc}}$. A further issue with running statistical analyses on values of $\dot{V}_{\mathrm{O}_{2}}$ est is that the estimate errors associated with them create SEs that are larger than those associated with the equivalent $f_{\mathrm{Hdc}}$ values, thus increasing the chances of Type II errors during statistical analysis. However, according to the Fick equation, if cardiac stroke volume and tissue oxygen extraction do not change, or both vary systematically, increases in $f_{\mathrm{H}}$ will result in increases in $\dot{V}_{\mathrm{O}_{2}}$ (Froget et al. 2001). Furthermore, there are indeed statistically significant differences between certain values of $\dot{V}_{\mathrm{O}_{2}}$ est derived from mean values of $f_{\mathrm{Hdc}}$ for the binned diving variables data (Table 2), supporting some of the statistically significant main effects revealed by the GLM. Thus the present study focused on variations in $f_{\mathrm{Hdc}}$ reported by the GLM, where statistically significant differences in $f_{\mathrm{Hdc}}$ are considered to suggest statistically significant differences in $\dot{V}_{\mathrm{O}_{2}}$. In the future, to enable detailed statistical comparisons to be made between values of $\dot{V}_{\mathrm{O}_{2}}$ est rather than $f_{\mathrm{H}}$, the SEs around values of $\dot{V}_{\mathrm{O}_{2}}$ est need to be smaller. This should be possible through the development of further conversion equations that 
include more predictor variables and thus have narrower confidence intervals. Such variables would need to be fixed measurements that would not therefore need to be measured while the bird is in the field (such as morphometric variables; Fahlman et al. 2005, Halsey et al. 2007). Without such improvements, this study exemplifies the limits of using $f_{\mathrm{H}}$ to estimate $\dot{V}_{\mathrm{O}_{2}}$ for discriminating between the costs of different diving behaviours.

\section{Characteristics of foraging dives and effects on $\boldsymbol{f}_{\mathrm{Hdc}}$}

In penguins, as well as in other species of deep-diving birds, there is evidence that longer dives are energetically more efficient, i.e. $\dot{V}_{\mathrm{O}_{2}}$ is lower (Bevan et al. 1992, Enstipp et al. 2001, Green et al. 2003, Halsey et al. 2005). The findings of the present study, comparing dive duration to $f_{\mathrm{Hdc}}$ agree with this trend (Table 2). A number of studies have found that $f_{\mathrm{H}}$ during periods at the surface between dives are on average higher than $f_{\mathrm{H}}$ during foraging dives (Woakes \& Butler 1983, Enstipp et al. 2001, Green et al. 2003, Froget et al. 2004). However, it cannot be concluded from this that $\dot{V}_{\mathrm{O}_{2}}$ during surface periods, i.e. oxygen consumed at the cellular level to fuel metabolism, is higher than that during dives, at least in part because diving animals are not only consuming oxygen at the surface but are also replenishing their oxygen stores. Nonetheless, the results from the current study suggest that, in king penguins, surface periods after foraging dives are indeed more costly in terms of $\dot{V}_{\mathrm{O}_{2}}$ than the foraging dives themselves. This is because dive cycles with longer surface durations, accounting for a number of variables such as dive duration and maximum depth, had a higher mean $f_{\mathrm{H}}$. In other words, increasing the duration of the surface portion of a foraging dive increases the mean $f_{\mathrm{H}}$ of the whole dive cycle and thus the $\dot{V}_{\mathrm{O}_{2}}$ est of the dive cycle (if the reverse were true and surface periods were less energetically expensive than the proceeding foraging dive, then $\dot{V}_{\mathrm{O}_{2}}$ est of dive cycles would decrease as surface duration increased).

The present study has also shown that, at least for king penguins, after accounting for dive duration, the $f_{\mathrm{Hdc}}$ of foraging dives is lower when the bottom duration of the dive is longer. Deep diving penguins experience a large reduction in buoyancy during the bottom phases of dives due to compression of trapped air. Furthermore, penguins are known to adjust their buoyancy prior to a dive to reduce the energy costs of buoyancy while they are submerged (Sato et al. 2002). At least in some cases, this may be specifically to achieve an even lower buoyancy during the bottom phase of the dive (Wilson \& Zimmer 2004). Thus dives with longer bottom durations are presumably dives with longer periods of low $f_{\mathrm{H}}$, which may explain how the $f_{\mathrm{Hdc}}$ of the dive cycle is lower.

The difference in $f_{\mathrm{Hdc}}$ for different depths of foraging dives was not statistically significant when other variables such as dive duration were accounted for. The issue over whether deeper dives will be more or less energetically demanding is complex (Halsey et al. 2006). However, the lack of difference in $f_{\mathrm{Hdc}}$ in foraging dives of different depths offers support to the theory that penguins adjust their buoyancy to compensate for the depth of dives they undertake (Sato et al. 2002) thus minimising the overall cost of the dive. In turn, this is likely to reduce the difference in costs of dives to different depths. Nevertheless, diving depth does have some influence on $f_{\mathrm{Hdc}}$. The decrease in $f_{\mathrm{Hdc}}$ afforded by an increase in the duration of the bottom phase of the dive is more pronounced in deep dives. Perhaps this is due to generally colder water temperatures at greater depths, with king penguins experiencing reductions in body temperature, enabling a reduction in metabolic rate (Handrich et al. 1997) that is greater when they stay at such depths for longer periods of time.

\section{Influence of wiggles on $\boldsymbol{f}_{\mathrm{Hdc}}$ during diving}

The present findings indicate a small but statistically significant effect of the number of wiggles on $f_{\mathrm{Hdc}}$ of deep dives, where an increase in wiggles produced an increase in $f_{\mathrm{Hdc}}$ (Fig. 4). One speculative explanation for this subtle finding is that prey at deeper depths are less visible and thus more costly to catch. However, in the main, the results in the present study suggest that the effect on $f_{\mathrm{Hdc}}$ of wiggles is not statistically significant in the king penguin.

The fact that king penguins are likely to be close to neutral buoyancy at the depths at which they feed may, at least in part, explain why wiggles are not costly (Sato et al. 2002, Wilson \& Zimmer 2004). However, it does seem somewhat surprising that the number of wiggles in a dive has a negligible effect on $f_{\mathrm{Hdc}}$. This is because wiggles often include periods of high acceleration, which can last for over $10 \mathrm{~s}$ in some cases (Ropert-Coudert et al. 2000b), and power requirements for swimming penguins is thought to increase as a cubed function of speed (Bannasch 1995). An alternative explanation for the findings in the present study is that wiggles are not adequately recorded using $2 \mathrm{D}$ dive profiles because feeding events often occur in the third dimension, which was not recorded. Bost et al. (2007) report that oesophageal temperature recordings married with wiggle data indicate that king penguins mostly catch a single prey per wiggle. In turn, the estimate by Pütz et al. (1998) that king penguins capture on average $44.3 \mathrm{~g}$ of food per foraging dive during the 
summer months implies that each prey item weighs, on average, $9 \mathrm{~g}$. However this is greater than the mean mass of prey caught by king penguins according to Kooyman et al. (1992) and Bost et al. (1997). If the estimations of Pütz et al. (1998) for total prey mass caught by king penguins per dive are accurate, then the calculations presented in the current study point to the possibility that not all feeding events are apparent as wiggles in $2 \mathrm{D}$ dive profiles.

\section{$f_{\mathrm{Hdc}}$ associated with dives of different shape}

Different dive shapes may represent different types of foraging behaviour, either because of the local environment in which the dive is performed e.g. water depth, and/or because of the nature of the prey, e.g. their density and type (Schreer et al. 2001). The present study used dive-shape classifications developed by Halsey et al. (in press) to categorise foraging dives into 3 shapes, namely $\mathrm{u}, \mathrm{U}$ and $\mathrm{W}$.

Dive duration and surface duration did not differ between the 3 dive-shapes, however there were differences both in bottom duration and maximum dive depth (Fig. 5). Furthermore, the number of wiggles differed between dive shapes, with the most wiggles occurring in $\mathrm{W}$-dives and least occurring in $\mathrm{u}$ dives. While it is expected that $\mathrm{u}$ dives include the smallest number of wiggles and the shortest bottom durations, it is interesting to note that they are also the deepest shape of dive (Fig. 5). This tends to support the view that $\mathrm{u}$ dives are searching dives (Wilson 1995), i.e. large arcing dives designed to explore a substantial portion of the water column. In terms of $f_{\mathrm{Hdc}}$ and thus $\dot{V}_{\mathrm{O}_{2}}$ est during diving in king penguins, categorising foraging dives by their shape does not create noteworthy differences, despite the statistically significant differences in certain diving parameters. Indeed, the differences in $f_{\mathrm{Hdc}}$ between shapes was even less when other diving parameters were taken into account. The possibility remains, however, that the categories of dives used in the present study do not effectively segregate the different types of foraging dives, if any, undertaken by king penguins, masking the differences in costs between truly different types of foraging dive. Additional data alongside dive shape such as swim speeds may improve classification of different types of foraging dive (Lesage et al. 1999).

\section{Variations in $f_{H}$ over dive cycles and ecological implications}

It is possible to begin considering under what foraging conditions, at least during the summer, king pen- guins are more likely and less likely to experience reproductive success due to their energy expenditure at sea, as suggested by $f_{\mathrm{Hdc}}$. The main effects and coefficients of the GLM indicate that when king penguins have to undertake very deep, relatively short dives, in particular when those dives are short due to a short bottom period, $f_{\mathrm{Hdc}}$ of foraging dives is relatively high. Furthermore, such dives might be undertaken when the only available food is deeper in the water column and is more scarce. For example, this tends to be the case in the waters around Crozet in comparison to the Polar front. In the latter area, myctophid fish, a primary food source of king penguins, exist in denser populations (Sabourenkov 1991, Pakhomov et al. 1994) and, according to indirect evidence, inhabit shallower depths (Park et al. 1993, Charrassin \& Bost 2001). These findings support the suggestions of Monaghan et al. (1994) and Green et al. (2005) that increases in the costs of dives are likely to represent an increase in the difficulty of obtaining food.

Whether such an increase in diving effort is related to a decrease in food availability or not, periods when deep, short dives with short bottom durations and long surface durations are undertaken may in king penguins represent periods of increased vulnerability to reproductive failure. This is because king penguins fast when breeding ashore, and thus breeding success depends primarily on mass gain while at sea plus food stored in the stomach for chicks, as is the case for most seabirds (Le Maho et al. 1993, Gauthier-Clerc et al. 2001, Mori 2001).

However, as Fig. 2 shows, the differences in $f_{\mathrm{Hdc}}$ due to changes in dive characteristics, although sometimes statistically significant, are never particularly large. Thus it might be reasonable to expect that changes in foraging behaviour are not likely to have a large effect on the energy costs of foraging dives for king penguins (although this does not necessarily mean that the effect is biologically unimportant). This can be demonstrated by comparing the foraging behaviour and $f_{\mathrm{Hdc}}$ of the birds diving in the second and third field seasons, which were all at the same stage of the breeding cycle. Birds during Field Season 3 had statistically significantly longer dive durations and bottom durations than birds during Field Season 2 (Fig. 1). The directions of these variables, which have been shown in the present study to influence on the $f_{\mathrm{Hdc}}$ of dives, is to predict a lower $f_{\mathrm{Hdc}}$ in the third field season compared to that during the second. Further, while surface duration and maximum dive depth did not differ statistically significantly between the 2 seasons, the direction of difference also supported a decrease in $f_{\mathrm{Hdc}}$ in Season 3. The value of mean $f_{\mathrm{Hdc}}$ of the dive cycle was indeed lower in Field Season 3 (Fig. 1) as predicted by the findings of the GLM, but however was not statistically signifi- 
cantly. Thus the differences in dive time budgeting had only a relatively subtle effect on $f_{\text {Hdc }}$. Given that the birds in Field Season 3 gained weight while at sea far more rapidly than the birds in Field Season 2 (and exhibited statistically significantly more wiggles per dive), it may be the case that the relationship that between diving behaviour and foraging success in king penguins is more obvious than between diving behaviour and $f_{\mathrm{Hdc}}$. In other words, changes in behaviour represent relatively small changes in the energetic costs of foraging but large changes in foraging success. This may hold true for other marine predators as well. Such a finding is important when considering the most effective ways of using such species to monitor the marine environment.

Acknowledgements. This project would not have been possible without the support of the people of the 40th, 41st and 42nd missions in Crozet. This study was funded by a grant from the Natural Environment Research Council (NERC), UK (ref: NER/A/S/2000001074), with financial support also provided by IPEV (Institut Paul Emile Victor). Ethical approval for all procedures was granted by the ethics committee of the French Polar Research Institute (IPEV) and of the Ministère de l'Environnement. We also followed the provisions of the United Kingdom Animal (Scientific Procedures) Act 1986, especially those set out by the Home Office in the Official Guidance on the operation of the Act.

\section{LITERATURE CITED}

Bannasch R (1995) Hydrodynamics of penguins: an experimental approach. In: Dann P, Norman I, Reilly P (eds) The penguins. Surrey Beatty \& Sons, Sydney, p 141-176

Bevan RM, Keijer E, Butler PJ (1992) A method for controlling the feeding behaviour of aquatic birds: heart rate and oxygen consumption during dives of different duration. J Exp Biol 162:91-106

Bevan RM, Butler PJ, Woakes AJ, Prince PA (1995) The energy expenditure of free-ranging black-browed albatrosses. Phil Trans R Soc Lond 350:119-131

Bevan RM, Butler PJ, Woakes AJ, Boyd IL (2002) The energetics of gentoo penguins, Pygoscelis papua, during the breeding season. Funct Ecol 16:175-190

Bost CA, Georges JY, Guinet C, Cherel Y and 6 others (1997) Foraging habitat and food intake of satellite-tracked king penguins during the austral summer at Crozet Archipelago. Mar Ecol Prog Ser 150:21-33

Bost CA, Handrich Y, Butler PJ, Fahlman A, Halsey LG, Woakes AJ, Ropert-Coudert Y (2007) Change in dive profiles as an indicator of feeding success in king and Adélie penguins. Deep-Sea Res II 50:248-255

Boyd IL, Woakes AJ, Butler PJ, Davis RW, Williams TM (1995) Validation of heart rate and doubly labelled water as measures of metabolic rate during swimming in California sea lions. Funct Ecol 9:151-160

Charrassin JB, Bost CA (2001) Utilisation of the oceanic habitat by king penguins over the annual cycle. Mar Ecol Prog Ser 221:285-297

Charrassin JB, Bost CA, Pütz K, Lage J, Dahier T, Zorn T, Le Maho Y (1998) Foraging strategies of incubating and brooding king penguins Aptenodytes patagonicus. Oecologia 114:194-201
Charrassin JB, Le Maho Y, Bost CA (2002) Seasonal changes in the diving parameters of king penguins (Aptenodytes patagonicus). Mar Biol 141:581-589

Cherel Y, Ridoux V (1992) Prey species and nutritive value of food fed during summer to king penguin Aptenodytes patagonica chicks at Possession Island, Crozet Archipelago. Ibis 134:118-127

Croxall JP, Reid K, Prince PA (1999) Diet, provisioning and productivity responses of marine predators to differences in availability of Antarctic krill. Mar Ecol Prog Ser 177: 115-131

Culik BM, Pütz K, Wilson RP, Allers D, Lage J, Bost CA, Le Maho Y (1996) Diving energetics in king penguins (Aptenodytes patagonicus). J Exp Biol 199:973-983

Enstipp MR, Andrews RD, Jones DR (2001) The effects of depth on the cardiac and behavioural responses of doublecrested cormorants (Phalacrocorax auritus) during voluntary diving. J Exp Biol 204:4081-4092

Fahlman A, Handrich Y, Woakes AJ, Bost CA, Holder RL, Duchamp C, Butler PJ (2004) Effect of fasting on the $\dot{V}_{\mathrm{O}_{2}}-f_{\mathrm{H}}$ relationship in king penguins, Aptenodytes patagonicus. Am J Physiol (Regul Integr Comp Physiol) 287: R870-R877

Fahlman A, Schmidt A, Handrich Y, Woakes AJ, Butler PJ (2005) Metabolism and thermoregulation during fasting in king penguins, Aptenodytes patagonicus, in air and water. Am J Physiol (Regul Integr Comp Physiol) 289: R670-R679

Froget G, Butler PJ, Handrich Y, Woakes AJ (2001) Heart rate as an indicator of oxygen consumption: influence of body condition in the king penguin. J Exp Biol 204: 2133-2144

Froget G, Butler PJ, Woakes AJ, Fahlman A, Kuntz G, Le Maho Y, Handrich Y (2004) Heart rate and energetics of free-ranging king penguins (Aptenodytes patagonicus). J Exp Biol 207:3917-3926

Gauthier-Clerc M, Le Maho Y, Gendner JP, Durant J, Handrich Y (2001) State-dependent decisions in long-term fasting king penguins, Aptenodytes patagonicus, during courtship and incubation. Anim Behav 62:661-669

Green JA, Butler PJ, Woakes AJ, Boyd IL, Holder RL (2001) Heart rate and rate of oxygen consumption of exercising macaroni penguins. J Exp Biol 204:673-684

Green JA, Butler PJ, Woakes AJ, Boyd IL (2003) Energetics of diving in macaroni penguins. J Exp Biol 206:43-57

Green JA, Boyd IL, Woakes AJ, Warren NL, Butler PJ (2005) Behavioural flexibility during year-round foraging in macaroni penguins. Mar Ecol Prog Ser 296:183-196

Halsey LG, Woakes AJ, Butler PJ (2003) Testing optimal foraging models for air-breathing divers. Anim Behav 65: 641-653

Halsey LG, Butler PJ, Woakes AJ (2005) Breathing hypoxic gas affects the physiology as well as the diving behaviour of tufted ducks. Physiol Biochem Zool 78:273-284

Halsey LG, Blackburn TM, Butler PJ (2006) A comparative analysis of the diving behaviour of birds and mammals. Funct Ecol 20(5):889-899

Halsey LG, Fahlman A, Handrich Y, Schmidt A, Woakes AJ, Butler PJ (2007) How accurately can we estimate energetic costs in a marine top predator, the king penguin? Zoology 110:81-92

Halsey LG, Bost CA, Handrich Y (in press) A thorough and quantified method for classifying seabird diving behaviour. Polar Biol

Handrich Y, Bevan RM, Charrassin JB, Butler PJ, Putz K, Woakes AJ, Lage J, Le Maho Y (1997) Hypothermia in foraging king penguins. Nature 388:64-67 
Hastie G, Rosen D, Trites A (2006) The influence of depth on a breath-hold diver: Predicting the diving metabolism of Stellar sea lions (Eumetopias jubatus). J Exp Mar Biol Ecol 336:163-170

Kooyman GL, Davis RW (1982) Diving depths and energy requirements of king penguins. Science 217:726-727

Kooyman GL, Cherel Y, Le Maho Y, Croxall JP, Thorson PH, Ridoux V, Kooyman CA (1992) Diving behaviour and energetics during foraging cycles in king penguins. Ecol Monogr 62:143-161

Le Maho Y, Gendner JP, Challet E, Bost CA and 5 others (1993) Undisturbed breeding penguins as indicators of changes in marine resources. Mar Ecol Prog Ser 95:1-6

Lesage V, Hammill MO, Kovacs K (1999) Functional classification of harbor seal (Phoca vitulina) dives using depth profiles, swimming velocity, and an index of foraging success. Can J Zool 77:74-87

Monaghan P, Walton P, Wanless S, Uttley JD, Burns MD (1994) Effects of prey abundance on the foraging behaviour, diving efficiency and time allocation of breeding guillemots Uria aalge. Ibis 136:214-222

Mori Y (2001) Individual diving behavior, food availability and chick growth rates in chinstrap penguins. Waterbirds 24 : 443-445

Pakhomov EA, Perissinotto R, McQuaid CD (1994) Comparative structure of the macrozooplankton/micronecton communities of the Subtropical and Antarctic Polar Fronts. Mar Ecol Prog Ser 111:155-169

Park YH, Gambéroni L, Charriaud E (1993) Frontal structure, water masses, and circulation in the Crozet basin. J Geophys Res 98:12361-12685

Pütz K, Cherel Y (2005) The diving behaviour of brooding king penguins (Aptenodytes patagonicus) from the Falkland Islands: variation in dive profiles and synchronous underwater swimming provide new insights into their foraging strategies. Mar Biol 147:281-290

Pütz K, Wilson RP, Charrassin JB, Raclot T and 5 others (1998) Foraging strategy of king penguins (Aptenodytes patagonicus) during summer at the Crozet Islands. Ecology 79: 1905-1921

Editorial responsibility: Rory Wilson (Contributing Editor), Swansea, UK
Ropert-Coudert Y, Bost CA, Handrich Y, Bevan RM, Butler PJ, Woakes AJ, Le Maho Y (2000a) Impact of externally attached loggers on the diving behaviour of the king penguin. Physiol Biochem Zool 73:438-445

Ropert-Coudert Y, Sato K, Kato A, Charrassin JB, Bost CA, Le Maho Y, Naito Y (2000b) Preliminary investigations of prey pursuit and capture by king penguins at sea. Polar Biosci 13:101-112

Sabourenkov EN (1991) Mesopelagic fish of the Southern ocean-summary results of recent Soviet studies. In: Selected scientific papers. Scientific Committee for Conservation of Antarctic Marine Living Resources (CCAMLR), Hobart, p 433-457

Sato K, Naito Y, Kato A, Niizuma Y and 5 others (2002) Buoyancy and maximal diving depth in penguins: do they control inhaling air volume? J Exp Biol 205:1189-1197

Schreer JF, Kovacs KM, O'Hara Hines RJ (2001) Comparative diving patterns of pinnipeds and seabirds. Ecol Monogr 71: 137-162

Slater PJB, Lester NP (1982) Minimising errors in splitting behaviour into bouts. Behaviour 79:153-161

Walsberg GE, Hoffman TCM (2005) Direct calorimetry reveals large errors in respirometric estimates of energy expenditure. J Exp Biol 208:1035-1043

Wilson RP (1995) Foraging ecology. In: Williams TD (ed) The penguins. Oxford University Press, Oxford, p 81-106

Wilson RP, Zimmer I (2004) Inspiration by Magellanic penguins: reduced swimming effort when under pressure. Mar Ecol Prog Ser 278:303-307

Woakes AJ, Butler PJ (1983) Swimming and diving in tufted ducks (Aythya fuligula), with particular reference to heart rate and gas exchange. J Exp Biol 107:311-329

Woakes AJ, Butler PJ, Bevan RM (1995) Implantable data logging system for heart rate and body temperature: its application to the estimation of field metabolic rates in Antartic predators. Med Biol Eng Comput 33:145-151

Woehler E (1995) Consumption of Southern Ocean resources by penguins. In: Dann P, Norman I, Reilly P (eds) The penguins: ecology and management. Surrey Beatty \& Sons, Chipping Norton, p 267-291

Submitted: September 29, 2006; Accepted: January 30, 2007 Proofs received from author(s): July 31, 2007 